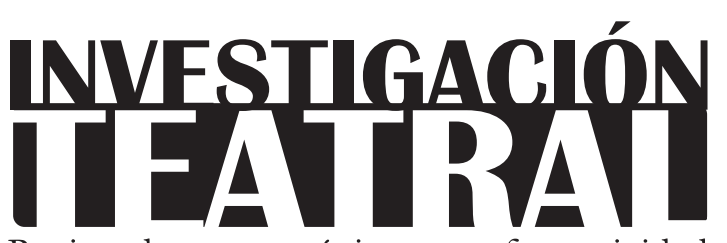

Revista de artes escénicas y performatividad

Vol. 9, Núm. 14

octubre 2018-marzo 2019

Segunda época

ISSN impreso: 1665-8728

ISSN electrónico: 2594-0953

Universidad Veracruzana

\title{
Bailando memoria(s) de mujer: dos escenas autobiográficas en territorio valenciano
}

\author{
Anna Albaladejo López*
}

\footnotetext{
* Universidad de Valencia, España.

e-mail: annaalbaladejolopez@gmail.com
}

Recibido: 16 de abril de 2018

Aceptado: 30 de julio de 2018 


\title{
Bailando memoria(s) de mujer: dos escenas autobiográficas en territorio valenciano
}

\section{Resumen}

En este artículo, la autora enfrenta una autobiografía colectiva presentada por mujeres creadoras provenientes, al igual que ella, de Valencia (España). Se analizan dos trabajos escénicos que parten del relato autobiográfico para desdoblarse en discursos colectivos de las mujeres, construyendo, así, una identidad propia, múltiple y fragmentaria: No soy yo (2016), de la bailarina y actriz Sandra Gómez, y Persona-l (2010), de la actriz y bailarina Maribel Bayona. La autora busca exponer una historia de creadoras que, desde la danza y el teatro, sumaron sus disciplinas para transformar las artes escénicas valencianas.

Palabras clave: memoria, artes escénicas, danza, transdisciplina, género, Valencia.

\section{Dancing Women's Memories: Two Autobiographical Performances in Valencian Territory}

\begin{abstract}
Based on the analysis of No soy yo (2016), by dancer and actress Sandra Gómez, and Persona-l (2010), by actress and dancer Maribel Bayona, the author approaches a collective autobiography of the female creators of her province, Valencia, Spain. Starting from the autobiographical, these two works develop into a collective discourse by women that construct their own multiple and fragmentary identities. It is the story of particular dance and theater creators who join their disciplines to transform the Valencian performing arts.
\end{abstract}

Keywords: memory, performing arts, dance, transdisciplinarity, gender, Valencia. 


\section{Bailando memoria(s) de mujer: dos escenas autobiográficas en territorio valenciano}

\section{Aclaración inicial: bailando en primera persona con las creadoras}

$\mathrm{E}$

n consonancia con un estudio que plantea la exploración autobiográfica en el terreno de la(s) escena(s) en expansión ${ }^{1}$-a través de las piezas Persona-l (2010) de Maribel Bayona y No soy yo (2016) de Sandra Gómez (dos actrices y bailarinas valencianas)-, debo hacer una advertencia que tiene que ver con mi mirada.

En concreto, con la distancia de mi mirada, pues debo advertir que acometo este artículo desde un lugar de implicación absoluta. Espacio del que me apropio, por defecto, como creadora que comparte generación y territorio con las dos mujeres cuyas piezas estudio, y por decisión, como investigadora que estudia su propio contexto desde la participación práctica en él. Con esto no me eximo de utilizar las herramientas de observación crítica, sino que las sumo a mi propia experiencia vivencial - de la que no puedo prescindir, puesto que las dos artistas son compañeras de batallas creativas en mi realidad presente-. Y es esta

1 Partiendo de aquella expansión del campo autónomo teatral que tan bien explica José Antonio Sánchez en su conferencia "El Teatro en el campo expandido" (impartida en el Museo de Arte Contemporáneo de Barcelona, en 2007) y Rubén Ortiz aplica al contexto mexicano en Escena expandida. Teatralidades del siglo XXI (2015), me permito transformar el adjetivo "expandida" para convertirlo en acción. Expansión, acción presente que no se detiene, movimiento que dialoga y desborda los sucesivos modelos de escena que van generando los artistas. Ampliación del término con la que juego a expandir la teoría de estos autores como un ejercicio en el que me sumo a su misma propuesta, desbordándola. Usaré a lo largo del texto indistintamente las dos nomenclaturas: escena expandida y escenas en expansión, para referirme a estas prácticas. 
coincidencia de búsquedas y afectos, en un mismo tiempo, la que me sugiere empaparme de la perspectiva autobiográfica que ellas proponen y yo hago mía, para articular un esbozo de lo que podría ser algún día una autobiografía colectiva de la creación femenina en mi territorio: Valencia. ${ }^{2}$

Escribo, pues, en primera persona, porque creo en la mirada subjetiva explícita, no exenta de herramientas para articular la historia. Escribo en primera persona del plural porque creo en el común de las mujeres de las artes vivas valencianas, un amplio grupo de mujeres que a veces juntas, y otras revueltas, estamos bailando, actuando, escribiendo, performando, creando al fin cada vez con mayor resonancia en los escenarios públicos.

Una primera persona que también será diacrónica, porque que se sabe heredera de nuestras antecesoras del último tercio del siglo xx: teatreras, danzarinas, performers y artistas circenses, visibles e invisibles. Muchas, muchas mujeres creadoras en mi territorio que lideraron, casi siempre entre bambalinas, proyectos profundos y renovadores para la nueva y expandida escena de este siglo. Y quizás -y sobre todo- escribo en primera persona porque es lo único de lo que estoy segura: que la memoria de la escena es performática y se teje de memorias individuales, como las de Sandra Gómez y Maribel Bayona, como la mía; de reflejos subjetivos bailando en un espejo, el de la memoria colectiva: diversa, única, múltiple, construida como un círculo de primeras personas.

Implicación absoluta que reivindico como mujer investigadora y creadora en un contexto local-global, donde las mujeres creadoras e investigadoras seguimos sin habitar los espacios reales y simbólicos con la misma facilidad que los hombres (hay que bailar con ello). Por eso, al tiempo que dinamitamos los roles de género en nuestras prácticas y nos resistimos a los nuevos clichés que imponen las cuotas de discriminación positiva y el espejismo de lo políticamente correcto, siento necesario escribir nuestra memoria, actuar nuestra historia y bailar, bailar juntas un discurso que, sin duda, será en primera persona.

2 Para aquellos que no la conozcan, Valencia es una comunidad autónoma del Estado español compuesta por tres ciudades: Castellón, Valencia y Alicante, en la cual se reproducen a pequeña escala las dinámicas de centro y periferia de los repartos simbólicos, económicos y políticos de cualquier geografía. Es por eso que algunas veces el nombre de Valencia se refiere a la ciudad, y otras a todo el territorio. Y si bien es mi deseo desplazar los centros, debo advertir que mi pertenencia a la ciudad, además del inexistente acceso a estudios con una perspectiva interterritorial real, dificulta esta intención. Una disculpa de antemano a mis compañeras alicantinas y castellonenses por no ser capaz de visibilizarlas más. 


\section{Ejercicio de memoria: Movimiento para una historia colectiva de las mujeres creadoras valencianas}

Ya he dicho que este artículo es una oportunidad para tejer algunos nudos de una autobiografía colectiva, una historia que tiene muchos volúmenes bailados y actuados, pero pocos escritos en las programaciones oficiales. Una memoria no escrita que atraviesa las piezas que hoy analizo. Especialmente No soy yo (2016), donde Sandra Gómez recorre la trayectoria de varias coreógrafas valencianas inscribiéndolas en las páginas de una historia global, la de las exploraciones de la danza postmoderna.

Pero, además, se trata de una historia de la expansión e intercambio de los lenguajes escénicos hasta llegar a la transdisciplinariedad -mayor o menor-, común a las prácticas de la mayoría de las creadoras actuales en nuestro territorio. Ejemplo de la cual son las dos piezas aquí abordadas, que indistintamente actualizan herramientas del teatro, la danza, el audiovisual e incluso la performance. Con esta acción me uno a los esfuerzos por trazar cartografías de lo invisible, iniciados por otros investigadores e investigadoras en mi contexto: Xavier Puchades o Patricia Pardo, compañeros de la práctica escénica; Ramón Rosselló, a quien debo más de una orientación académica, o Carmen Giménez Morte, cuyo estudio sobre los inicios de la danza valenciana ha alumbrado también esta búsqueda. ${ }^{3}$

\section{Reflexiones sobre la participación de las mujeres en el territorio valenciano}

Para entender el contexto en el que trabajamos las mujeres de mi comunidad, es importante apelar a cifras como las que denuncia Patricia Pardo en su estudio sobre las mujeres dramaturgas y circenses:

Pero si hablamos de autoras, el resultado estremece; de 1996 a 2005, de las 64 obras de autores valencianos exhibidas en los teatros públicos, solo cuatro son de mujeres:

3 La labor de estos investigadores - desde el ámbito de la Universidad, en el caso de Rosselló y Giménez Morte; combinando práctica artística e investigación académica, en el caso de Xavier Puchades y Patricia Pardo- tiene un mérito especial en un territorio donde la investigación no es impulsada desde las instituciones públicas que gestionan las artes escénicas, que apenas es valorada en las formaciones prácticas que, por el momento, no se inscriben en ámbitos universitarios, y con una universidad en la que las áreas teatrales (imposible hablar de artes escénicas en general) han sido arrinconadas por otros ámbitos de investigación. En estas circunstancias, hacer estudios críticos, cuanto más si estos están referidos al género, requiere esfuerzos inestimables. 
Bailando memoria(s) de mujer: dos escenas autobiográficas en territorio valenciano

Anna Albaladejo López

Defensa de dama, de Isabel Carmona y Joaquín Hinojosa, Más sola que la una, de Ma. Ángeles Morales, Amors impossibles y Malas, de Patricia Pardo (31). ${ }^{4}$

Porcentaje que no se eleva demasiado en la última década, pese al reconocimiento público del aumento de dramaturgas visibles en el panorama español (hecho que ha suscitado artículos y ciclos entusiastas, pero que por desgracia no ha desembocado todavía en apoyos y programaciones regulares). ${ }^{5}$

Algunos datos recogidos por Pardo dan fe de que el aumento en la creación femenina de Valencia no ha tenido un reflejo paralelo en cuanto a su programación pública en los teatros oficiales. Cito dos ejemplos para ilustrar la programación de dos de los tres teatros públicos de la ciudad:

Talía (2005-2010). De 51 obras exhibidas de autoría valenciana, sólo dos corresponden a autoras en equipos mixtos. Teatro Rialto (2005-2010). De las 81 obras de autoría valenciana exhibidas, 6 son de autoras (en equipos mixtos) en programación "regular", y 5 son de autoras valencianas (en equipos mixtos) en programación "emergente" (Pardo 32). ${ }^{6}$

Cabe destacar que muchas mujeres creadoras de nuestro territorio quedan atrapadas ad infinitum en la categoría de "emergentes" (con menor presupuesto en subvención pública y programaciones más precarias) por sus mayores dificultades para consolidar estructuras empresariales estables en el tiempo. Uno más de los peces que se muerden la cola en cuestión de género, como demuestra otro de los datos sobre uno de los festivales más significativos de la programación pública valenciana: La Mostra d’Alcoi:

4 Però si parlem d'autores, el resultat estremeix: del 1996 fins el 2005, de les 64 obres d'autors valencians exhibides als teatres públics, només quatre són de dones: Defensa de dama, d'Isabel Carmona i Joaquín Hinojosa, Más sola que la una, de Ma Ángeles Morales, Amors impossibles i Malas, de Patrícia Pardo.

5 Ver el artículo "El año en que estallaron las dramaturgas" de Raquel Vidales disponible en el siguiente enlace: https://elpais.com/cultura/2016/04/27/actualidad/1461740645 037119.html. Un titular que refuerza una idea equivocada, en mi opinión, al hablar de creación femenina "reciente", en vez de "invisibilizada o sesgada" a lo largo de la historia. Aún más, hablar de un estallido puede dar la imagen de algo que no está consolidado ni tiene visos de perpetuarse.

6 Talia (2005-2010). De 51 obres d'autoria valenciana exhibides, només dues corresponen a autores en equips mixtos. Teatre Rialto (2005-2010). De les 81 obres d'autoria valenciana exhibides, 6 són d'autores valencianes (o equips mixtos), en programació "regular", i 5 són d'autores valencianes (o equips mixtos), en programació "emergents". 
INVESTIGACIÓNTEATRAL

Revista de artes escénicas y performatividad

Vol. 9, Núm. 14

octubre 2018-marzo 2019
Bailando memoria(s) de mujer: dos escenas autobiográficas en territorio valenciano

Anna Albaladejo López

De las 171 obras de teatro y circo exhibidas en los últimos 10 años, solo 11 las firman autoras valencianas. Son diferentes las críticas a la línea de programación de la Mostra acusada de tener una programación centrada en las obras de entretenimiento, donde se han focalizado y promocionado casi exclusivamente compañías nacidas en los 90, todas ellas dirigidas por gestores hombres y con un repertorio de obras de autoría firmadas por hombres siempre, dejando de lado sistemáticamente a compañías más jóvenes y de investigación. Podríamos decir que como la Mostra no cuenta con la creación contemporánea, tampoco cuenta con las obras firmadas por mujeres, porque ellas son quienes encabezan la mayor parte de las propuestas alternativas/contemporáneas de investigación actuales (34). ${ }^{7}$

Reflexión que entronca con una idea que hemos valorado las creadoras valencianas en algunos de nuestros encuentros: que la misma dificultad de acceso a los circuitos oficiales y de la cultura del entretenimiento ha permitido que muchas de nosotras nos independicemos de los modelos teatrales establecidos. Es decir que, desde un replanteamiento de expectativas de acceso a becas y programaciones comerciales, hemos asumido cierta renuncia a cambio de una libertad para explorar nuevos caminos que nos ha llevado a ocupar en Valencia ese terreno de la(s) escena(s) en expansión que, poco a poco, ha consolidado su reconocimiento académico y trata de acceder a los recursos de aquello que se considera oficialmente como Artes Escénicas.

Un último dato del estudio citado se refiere a la producción pública en el periodo 20052014 y es especialmente aterrador, puesto que se refiere a la única institución que realiza producción pública en Valencia:

Desde Culturarts-Teatres de la Generalitat sólo se ha producido una obra donde una mujer formaba parte del equipo de escritura: El cuarto paso (2006), Ciclo "Nuevas Dramaturgias", con textos de Rosa Molero, Gabi Ochoa, Jordi Gomar y Alberto Torres (41). ${ }^{8}$

7 De les 171 obres de teatre i circ exhibides al llarg dels deu últims anys, només 11 les signen autores valencianes. Són diferents les crítiques a la línia programativa de la Mostra, acusada de tindre una programació centrada en les obres d'entreteniment, on s'ha focalitzat $i$ promocionat gairebé exclusivament companyies nascudes als 90, totes elles dirigides per gestors homes i amb un repertori d'obres d'autoria signada per homes sempre (Alberola, Alapont, Cardeña, García...), fent de costat sistemàticament les companyies més joves o d'investigació. Podríem dir que com la Mostra no compta amb la creació més contemporània tampoc no compta amb les obres signades per dones, perquè són elles qui encapçalen la major part de les propostes alternatives/contemporànies/d'investigació actuals.

8 Des de Culturarts-Teatres de la Generalitat només s'ha produït una obra on una dona formava part de 
Dado que el estudio finaliza en 2014 y no aborda el importante giro político del gobierno de la Comunidad Valenciana, ${ }^{9}$ vamos a sumar algunas reflexiones respecto al nuevo periodo, aún breve. A priori, es destacable el deseo de apoyar a la creación femenina del nuevo equipo de dirección artística de Artes Escénicas, encabezado por Roberto García, de lo que ahora se conoce como Instituto Valenciano de la Cultura (IVC), que sugiere también una cierta apertura hacia propuestas innovadoras respecto al modelo dramático tradicional. En cuanto al género, no sólo se incluye ahora un criterio de paridad respecto a la concesión de ayudas a proyectos de creación, sino que además han aparecido iniciativas tan interesantes como la Residencia de Creación Insula Dramataria Josep Lluís Sirera, en cuya primera edición (2017-2018) se ha optado por el impulso exclusivo a la dramaturgia femenina a través de la selección de seis autoras: Mafalda Bellido, María Cárdenas, Begoña Tena, Maribel Bayona, Laura Sanchís y Antonia Bueno. En dicho contexto, cada una de ellas desarrolló un texto propio durante un laboratorio de escritura teatral de varios meses de duración, trabajos que fueron apoyados por sendos tutores. Sin embargo, sigue surgiendo la pregunta de hasta qué punto es posible desplazar las centralidades históricas, cuando otra de las novedosas iniciativas de visibilidad de la creación valenciana, el ciclo Maestros de la Palabra (inaugurado en febrero de 2018), presenta solamente trabajos de tres autores varones. Tengo la esperanza, no obstante, de que las iniciativas del IVC consigan en tiempos muy próximos que la paridad sea cotidiana, además de simbólica, y que las mujeres dramaturgas seamos reconocidas como maestras y no sólo como talentosas aprendices.

Para seguir con este trazado autobiográfico colectivo es imprescindible adentrarnos ahora en el territorio de la danza, algo relevante no solamente para contextualizar los trabajos de Maribel Bayona y Sandra Gómez (bailarinas además de actrices), sino por su significación en la historia de la creación femenina en nuestra tierra. Sin temor a equivocarme, puedo decir que las primeras mujeres que lideran compañías aquí son precisamente las bailarinas, como atestiguan los datos proporcionados por Carmen Giménez Morte, en su estudio La danza contemporánea en la Comunidad Valenciana. Los primeros pasos (2001).

Seguramente, por ser la danza un espacio tradicionalmente protagonizado por mujeres, los estudios estadísticos y descriptivos no incorporan una reivindicación explícita de género. Sin embargo, en la comparativa con estudios sobre la participación femenina en las

l'equip d'escriptura: El cuarto paso (2006), Cicle "noves dramatúrgies", amb textos de Rosa Molero, Gabi Ochoa, Jordi Gomar i Alberto Torres.

9 Con un cambio de gobierno de coalición de izquierdas (Compromís, Podemos y PSOE) que desplazaba 24 años de gobiernos extremadamente conservadores e indiferentes - por no decir opuestos- al desarrollo cultural y sus manifestaciones críticas. 
Bailando memoria(s) de mujer: dos escenas autobiográficas en territorio valenciano

Anna Albaladejo López

empresas y compañías teatrales de los años 90, como el de Ramón Rosselló, ${ }^{10}$ es fácil visualizar que en esta etapa los espacios de liderazgo de las mujeres en proyectos y compañías de danza es mayor que el de sus compañeras de teatro y circo, como ilustraremos en seguida.

Antes de ello, quiero compartir algunas reflexiones provocadas por la consulta del informe "Danzar en precario. El sector de la danza en la Comunidad Valenciana", publicado en 2015 por la APDCV $^{11}$ en referencia a este territorio feminizado.

Las ayudas y subvenciones autonómicas a la danza nunca han superado el 16.45\% del total de las destinadas a las Artes Escénicas, muy lejos del 20\% reclamado durante años desde el sector ("Danzar en precario" 99).

Si bien podemos decir que, en general, los presupuestos para artes escénicas son menores comparados con otros ámbitos de la cultura, y a su vez que los presupuestos para cultura son menores que los de otros ámbitos disciplinales, este tanto por ciento ejemplifica claramente a lo que se enfrenta el sector de la danza en Valencia. Lo que lleva a decir a los profesionales valencianos en este mismo informe:

Los profesionales son conscientes de la nimiedad de la actual inversión pública y, en especial, de las ayudas públicas inexistentes, lo cual consideran un problema. Desde las compañías se lamentan de que las ayudas no sirvan para proyectos profesionales poco consolidados y los programadores sostienen que el apoyo que reciben es insuficiente para mantener las producciones en cartel más de unos pocos días (99-100).

Consciencia colectiva del poco espacio económico y de programación, por tanto simbólico, que los poderes públicos conceden a una danza valenciana que -como demuestra Giménez Morte a lo largo de todo su estudio- ha sido una de las pioneras en la renovación de la danza en todo el Estado español. Actividad dancística que no sólo ha proliferado en compañías de creación, escuelas formativas o exploración de nuevos lenguajes, ${ }^{12}$ sino que también ha sabido conectar con el público, como demuestra la afluencia de espectadores a la programación regular y a festivales públicos tan importantes como el ya veterano Dansa València (La danza contemporánea 105-121).

10 "Más allá de la interpretación: nuevas creadoras en el teatro valenciano actual".

11 Asociación de Profesionales de la Danza de la Comunidad Valenciana.

12 Un dato relevante al respecto es que el Conservatorio de Danza de Valencia sería, junto al Institut del Teatre de Barcelona, uno de los primeros centros en implementar la especialidad de Danza Contemporánea a finales de los años 80 . 
La situación de mayor precariedad en la danza frente a otras manifestaciones escénicas, denunciada por este estudio y otros similares, tiene razones históricas complejas y diversas que exceden lo que puede abordarse en este artículo. Sin embargo, desde la mirada de una autobiografía de género -y siendo la danza la disciplina artística donde las mujeres ejercen con mayor frecuencia liderazgos en mi territorio-, sí es interesante reflexionar sobre los motivos por los cuales esta área cuenta con menos recursos públicos y foros de exhibición. ${ }^{13}$

Por otra parte, la lectura del estudio de Giménez Morte sugiere otras preguntas sobre el reparto de roles dentro del mismo campo:

Una de las actividades del Centro Coreográfico de la Comunidad Valenciana -creado en 1998- es la llamada "Célula de Inserción Profesional" que trata de conectar a los alumnos recién salidos de sus estudios de danza con el mundo profesional a través de 2 años de formación continuada. Dos profesores fijos en Danza Contemporánea y Danza Clásica: Leopoldo Santos y José Belda, junto a la labor de los prestigiosos pedagogos (Paco Maciá, Carmen Roché, Jeanne Solane, Martin Padrón, Mat Voorter, etc.) y coreógrafos (Carlos Iturrioz, Santiago Sempere, Paolo Mahovich, Ramón Baeza, David Zambrano, Mauro Galindo, Juan Carlos García, Vicente Sáez, Rami Leví, Inma Rubio, etc.) (142).

Esto sugiere una paradoja: si la gran mayoría de profesionales en activo a finales de los años 90 en Valencia eran mujeres, especialmente en el campo de la danza contemporánea, ¿cómo es posible que apenas encontremos a dos de ellas entre los responsables de formar a las nuevas generaciones? Se hace inevitable la metáfora de si bailarán invisibles bajo el "etc." con que Giménez Morte cierra el párrafo.

Por suerte, el cambio político operado en nuestro territorio (que se ha concretado con el cambio de dirección artística que antes comentábamos) parece enfocarse en este campo

13 Si bien habría que tener en cuenta muchos factores como, por ejemplo, el número de empresas o profesionales dedicados en nuestra comunidad a las distintas disciplinas de las artes escénicas, si observamos los presupuestos de 2018 destinados a las Ayudas al Fomento de las Artes Escénicas del IVC (475.752€ para el Sector de la Danza, frente a los 2.539.248 € destinadas a los Sectores Teatral y Circense), podemos entender las denuncias de APDVC y otras asociaciones de profesionales de la danza. No obstante, el tema del reparto es complejo, puesto que dentro de las Ayudas de Teatro y Circo también es desigual la adjudicación de recursos entre disciplinas (Circo recibe mucho menos que Teatro), lenguajes artísticos (los criterios siguen primando ciertos modelos dramáticos) o estructuras de gestión (el modelo empresarial piramidal sigue siendo primado frente a otros más horizontales). Por lo que, ciertamente, la cuestión del género es un tema que demanda de una atención explícita, pero no exenta de relacionarse con otros factores. 
con un decidido apoyo a las cuestiones de género. Se trata de un impulso que celebramos en la edición 2018 de Dansa València, cuyo título dio la medida de un eje vertebrador de apoyo a la creación femenina: Elles es mouen. El festival, bajo la dirección ganada en concurso público por Mar Jiménez, apuesta por la programación de compañías de creación integradas por mujeres: Ángela Verdugo, Fil d'Arena, Malarte, Titoyaya, Pepa Cases, Sol Pico, Marea Danza, e incluye la presentación de proyectos como Las muchas de Ma. Antonia Oliver, que se adentran directamente en la cuestión del cuerpo femenino trayendo a escena a mujeres mayores.

Y cerrando el breve repaso sobre la situación de acceso desigual a los recursos, que todavía padecemos las mujeres de las artes escénicas en Valencia, me gustaría transformar el tono de mi biografía comunitaria para pasar de la denuncia a la puesta en valor. Como acto de empoderamiento en primera persona, voy a decir que las mujeres creadoras en Valencia hemos sido capaces de transformar nuestra situación periférica en una posibilidad. De manera que la quasi marginalidad nos ha convertido (junto a otros compañeros varones que han optado también por la experimentación) en impulsoras de la transformación de lenguajes y prácticas en el imaginario de las artes escénicas valencianas. Poco a poco el desplazamiento de los centros disciplinales va llegando a los escenarios públicos, y esperemos que suponga un mayor acceso de las mujeres a éstos.

\subsection{Una autobiograf ía colectiva y transdisciplinar}

Lo que ya no tiene vuelta atrás, a finales de la segunda década del siglo XXI, es la acción plena de las mujeres en los campos creativos. Espacio conquistado apenas entre las grietas, pero indiscutible. Por ello, esta autobiografía se conforma como un ejercicio de sororidad, que diluye en una historia conjunta las distinciones tradicionales entre disciplinas, fronteras que dejan de tener sentido en las articulaciones heterogéneas de los proyectos contemporáneos.

De esta manera, voy a proponer un esbozo (apenas un listado) que recoge una compilación de nombres femeninos de la danza, el teatro y el circo valencianos, desde finales de los años 70 hasta el presente. ${ }^{14}$ Esto representa un esfuerzo por consignarnos, que algún día

14 Si bien las prácticas performativas son hoy por hoy otra de las confluencias en la escena expandida valenciana, su campo de acción, y por tanto sus creadoras y creadores, se han desarrollado en circuitos propios, a veces por decisión propia y otras por supervivencia frente a los modelos totalizantes del teatro y la danza. Mujeres como Lucía Peyró, Ángela Gracia, Lorena Izquierdo o Yolanda Benelva, entre otras, han trabajado a lo largo de los años en los márgenes de la institución escénica, aportando herramientas 
espero poder ampliar a profundidad. Me remitiré para ello a los estudios ya mencionados, ampliando el panorama con investigaciones propias.

\section{Nuestras antecesoras}

Desde finales de los años 70 y especialmente en la década de los 80 , cada vez más mujeres se hacen visibles en el campo de la creación escénica valenciana. Muchas veces, especialmente las mujeres de teatro y circo, lo harán como actrices-creadoras en compañías mixtas, donde sus aportaciones son fundamentales para la exploración y renovación de lenguajes, aunque casi nunca firmen los trabajos en primera persona. Es el caso de Amparo Mayor, dentro de PTV Clown; Ma. Josep Conga, en Pluja Teatre; Maite Miralles, dentro del proyecto de compañía y espacio teatral La Estrella; Empar Claramunt, en Teatro Buffo; Rosa Navarro, en el seno de Lluerna Teatre; Cristina Macià con La Carátula, o María Colomer, en La Mar Salá. La mayoría de ellas se ubican en ese territorio de fronteras reversibles que es el circo teatral para niñas/os y adultos. Otra figura importante por su incorporación al mundo de la dirección es Carme Portaceli, una de las primeras directoras de la escena española.

Pero, como comentaba en párrafos anteriores, serán las mujeres de la danza las más visibles como líderes de compañías -ellas solas o acompañadas por varones-durante estas décadas. Mujeres con grandes deseos de experimentar las nuevas fórmulas artísticas que descubren en sus viajes al extranjero, que van a ser especialmente relevantes en el camino hacia una de las primeras prácticas interdisciplinares en nuestra tradición: la danza-teatro, espacio de posibles entre el movimiento, la palabra, el mimo, las artes plásticas o el audiovisual. Micaela Torres y Rosángeles Valls, primero en So i Moviment y más adelante en Ananda Dansa; Anabel Conesa, dentro de giap Danza; Olga García Poliakov, con su grupo Vaganovas; Antonia Andreu, y Gracel Meneu, en Vianants Dansa, son algunos de los nombres más conocidos.

Todas estas mujeres seguirán activas durante los años 90 y la mayoría siguen vinculadas a nuestra escena en el presente (2018), sirviendo de referencia a nuevas incorporaciones femeninas. Entre estas últimas podemos nombrar a María Muñoz, en la Compañía Mal Pelo; Cristina Andreu y Cora Mateu, cofundadoras, junto a otros bailarines, de La Sonrisa de Caín; Mar Gómez y Lipi Hernandez, que fundan junto a otras bailarinas el grupo de Las Malqueri-

de exploración de las que hoy nos servimos muchas creadoras. Sería mi deseo incluirlas en un estudio posterior, con más tiempo para conocer a profundidad sus trayectorias. 
das; Ana Extremiana, Gemma Gisbert, Maite Bacete, Eva López ${ }^{15}$ y otras que, como Sol Picó, se inician en nuestro territorio, pero continúan su trayectoria en Barcelona o Madrid.

Por su parte, muchas actrices empiezan también a desplazar sus competencias hacia la dirección y la dramaturgia, aunque su visibilidad será mayor ya a partir del año 2000. Entre éstas se encuentran Isabel Requena, Victoria Salvador, Isabel Carmona, Imma Sancho, Marta Roig, Cristina Fenollar, Lola López o Amparo Vayá, entre otras. Especial mención merece el caso de Pilar Almería, que compagina su faceta actoral con la gestión y dirección del teatro El Micalet.

\section{Nosotras, las creadoras liminales del siglo XXI}

Ya llegando a mi propia generación, es a principios del año 2000 cuando las mujeres del campo teatral nos incorporamos plenamente a terrenos hasta el momento poco habitados -como los de la dramaturgia y la dirección-, sin renunciar por ello a colocar nuestros cuerpos en escena, como demuestra el hecho de que la mayoría de creadoras actuales somos, al mismo tiempo, actrices y bailarinas.

El hecho se destaca en el estudio de Ramón Rosselló, que hace un seguimiento cronológico en el que señala a la actriz y payasa Patricia Pardo como la primera autora teatral de reconocimiento público, convocada a escribir de forma individual o colectiva (siempre como única mujer entre varones) por diversas compañías teatrales desde finales de los años 90. Siendo casi contemporánea, Rosa Molero es la única autora, mencionada por Rosselló, que se dedica exclusivamente a la escritura a finales de los años 90 y principios del 2000 (“Más allá de la interpretación" 88-90).

En los inicios del siglo xxI, el crítico destaca la incorporación a la escritura dramática de otras mujeres cuya formación inicial es actoral. Algunas en colectivos mixtos de creación, como Pau Pons, dentro del colectivo El Pont Flotant, o Maribel Bayona (cuya pieza, Persona-l, presentamos) y María José Guisado, dentro del equipo de Espacio Inestable (compañía teatral que también gestiona un espacio de programación independiente) (90-92). A estos referentes visibilizados por Rosselló -y sumando mi perspectiva transversal- se agrega el caso del colectivo "Los que quedan", en el que Sandra Gómez (la otra creadora que abordaremos en este texto) empieza su andadura creativa en los terrenos fronterizos de la danza, el teatro y la escena real. Otras, como Begoña Tena, Mónica Pérez y Anna Albaladejo, somos mencionadas en el artículo de Rosselló como primeras actrices y dramaturgas

15 Testimonios de algunas de estas coreógrafas y pedagogas de la danza son recogidos por Sandra Gómez en su pieza No soy yo (2016). 
que trabajan en solitario o en confluencias de creación colectiva puntual, como es el caso de La Imposible Cia. (colectivo desde el que he convocado, durante varios años, a grupos mixtos de actores-creadores para generar propuestas conjuntas).

Nombres a los que aún podemos sumar los de Sonia Alejo (que además de escribir, impulsa desde Castellón el más periférico de los teatros actuales en nuestra tierra: el teatro de calle), o Gemma Miralles y Eva Zapico (de las pocas que encaran la dirección escénica en creaciones propias o de encargo). Cabe aquí hablar también de Antonia Bueno, madrileña que se afinca en Valencia en esta época, pero perteneciente por edad y trayectoria a una generación anterior. Su labor de autoría y acicate del empoderamiento femenino, a través de iniciativas como la asociación Dones en Art, son especialmente relevantes en esta etapa.

Todas nosotras establecimos complicidades, desde nuestros inicios artísticos y laborales, con otras mujeres de la escena que han empezado a ocupar espacios de dirección, con un enfoque de creación muchas veces participativa. Tal es el caso de la ya mencionada Eva Zapico en el ámbito teatral, así como de Rocío Pérez, Ángela Verdugo o la compañía Taiat Dansa, cuyos campos de acción se derivan del de la danza contemporánea. Ya llegando la segunda década del siglo, se suman a este último contexto algunas creadoras más jóvenes en colectivos muchas veces formados únicamente por mujeres. Es el caso de los distintos grupos que convoca Alicia Cubells; de compañías como La Lola Boreal (integrada por Aurora Diago, Helena Gómez y Cristina Gómez), o Fil d'Arena (en la que crean conjuntamente Clara Crespo, Isabel Abril, Irene Ballester y Roseta Placencia). Se trata de colectivos que generan trabajos con un fuerte componente de movimiento que, sin embargo, incorporan con toda normalidad también la palabra, los medios audiovisuales y la acción teatral o performática.

Este uso indistinto de lenguajes es también práctica común en jóvenes colectivos femeninos cuya formación proviene del campo teatral, por ejemplo: Las Subterráneas (con Lucía Saéz, Esther Martínez y Lucía Abellán) o Maquinant Teatre (con Aina Gimeno, Ana Moret y Ana Ulloa). Caso especial es el de Carla Chillida, que pese a su raíz en el mundo de la danza funda una compañía de teatro político; A Tiro Hecho, que originalmente fue mixta, pero actualmente está liderada por un grupo de mujeres: Yarima Osuma, Margarida Mateos y Paula Romero.

Estas nuevas prácticas han transformado también a la escritura, incorporando, entre otros elementos, la dimensión autobiográfica en los textos de numerosas mujeres que ocupan ya con total confianza el lugar de la autoría desde las tres provincias valencianas. Es el caso de las castellonenses Mafalda Bellido y Nuria Vizcarro, las valencianas Guadalupe Sáez y Merche Aguilar, o la alicantina Lola Blasco, ganadora del Premio Nacional de Literatura Dramática en 2016.

En el ámbito de la creación, nos encontramos también con una proliferación de grupos formados por mujeres, entre los que podemos destacar a La Cítrica (liderado por Ana Re- 
Anna Albaladejo López

benaque) y el Colectivo Circo 9.8 (impulsado por Silvia Navarro). De especial relevancia por su fusión transgresora de estéticas y discursos, de nuevo destaca la artista Patricia Pardo, cuya trayectoria clown cuenta con más de 20 años entre Nas Teatre y su compañía homónima.

Progresivamente y con especial entusiasmo en la década actual, las mujeres valencianas de la danza, el circo y el teatro hemos ocupado espacios de protagonismo y visibilidad en el rol de creadoras. A veces liderando en solitario, otras en grupos que no sólo recogen el espíritu de la colectividad teatral, sino también la idea de la sororidad que apuntábamos anteriormente. Muchas mujeres se adentran en el terreno de la creación -de forma continuada o puntual- con la seguridad de habitar ese espacio con pleno derecho frente a los recursos y autoridades simbólicas tradicionalmente masculinas. ${ }^{16}$

Mujeres cuya práctica ha concretado aquellos desplazamientos disciplinares que apuntaban ya sus antecesoras de los años 80 y 90: intercambio de recursos, trasvase de lenguajes, transdisciplinariedad, nuevas estructuras de creación alternativas al modelo empresa-compañía, empoderamiento y ocupación de los espacios públicos; movilidad de roles y compañías, revisión de los modelos dramáticos y coreográficos, escrituras confesionales, ficciones y poéti-

16 Recojo aquí, a modo de listado-homenaje, más de 100 nombres de mujeres creadoras valencianas como ejemplo de las muchas más en activo en nuestro territorio: Aina Gimeno, África Hurtado, Alba Blanco, Alejandra Mandli, Alicia Cubells, Amparo Vayá, Ana La Cruz, Amparo Urieta, Ana Extremiana, Ana Millás, Ana Rebenaque, Andrea Pérez, Ángela Bermúdez, Angela Verdugo, Anna Albaladejo, Anna Marí, Anna Moret, Anna Ulloa, Antonia Bueno, Antonia Montaner, Aurora Diago, Beatriz Barquero, Begoña Tena, Belen Riquelme, Blanca Martínez, Carla Chillida, Carmen Parra, Carmen Valera, Carolina Boluda, Cesca Salazar, Claudia Zucheratto, Claudia Serra, Clara Crespo, Cora Mateu, Cristina Andreu, Cris Gomez, Cristina Fernández, Cristina Gómez, Cristina Núñez, Diana Bernal, Desirée Belmonte, Elena Martínez, Elisa Matallín, Empar Plà, Ester Martínez, Eugenia Sancho, Eva Bertomeu, Eva López, Eva Zapico, Gemma Miralles, Gracia Sánchez, Guadalupe Saez, Helena Gómez, Irene Ballester, Irene González, Isabel Abril, Isabel Caballero, Isabel Carmona, Isabel Requena, Isabel La bella, Isabel Martí, Jessica Belda, Jessica Martínez, Jimena Cavaletti, Juana Castellblanc, Kika Garcelán, Laia Sales, Lara Sanchís, Laura Miñarro, Laura Sanchís, Lola Blasco, Lorena López, Lourdes de la Rúa, Lola López, Lucía Abellán, Lucía Saez, Luna Soriano, Ma. José Guisado, Ma. José Peris, Mafalda Bellido, Maite Gil, Maite Miralles, Mamen Agüero, Mar Mandli, Margarida Mateos, María “Mariua”, María Cárdenas, María Colomer, María José Mora, Maribel Bayona, Maribel Bravo, Mariló Tamarit, Marina Izquierdo, Mariola Ponce, Marga Martín, Merce Tienda, Merche Aguilar, Merichell Barberá, Mónica Real, Nuria Vizcarro, Patricia Barrachina, Patricia Pardo, Pau Pons, Paula Llorens, Paula Miralles, Paula Romero, Paula Sebastián, Pepa Cases, Pepa Gómez, Raquel Hernández, Rocío Ladrón de Guevara, Rocío Perez, Rosa Fraj, Rosa Molero, Rosa Navarro, Rosana Mira, Rosangeles Valls, Roseta Placencia, Sandra Gómez, Silvia Navarro, Silvia Rincón, Sonia Alejo, Susana Solly, Tatiana Clavel, Tania Muñoz, Teresa Sánchez, Txetxe Folch, Victoria Enguídanos, Victoria Salvador, Yarima Osuna y Yolanda López. 
cas de realidad (ipara empujar la realidad!), y otra multitud de caminos que dialogan con nuestra tradición escénica local y global en esa ya imparable expansión de las escenas del mundo.

Ejemplo de lo mencionado son las dos piezas que aquí vamos a presentar: Persona- $l$ (2010) de Maribel Bayona y No soy yo (2016) de Sandra Gómez, con especial atención a su dimensión autobiográfica que -desde la perspectiva de género que hoy ocupamos- hace eco de aquella frase que atraviesa todos los feminismos desde los años 70: lo personal es político. ¿Y qué sería del arte sin política y sin subjetividad?

\section{Persona-l, de Maribel Bayona, y No soy yo, de Sandra Gómez. Dos prácticas autobiográficas en el intersticio de la danza y el teatro}

Decía al principio del artículo que fue la elección de las piezas de Maribel Bayona y Sandra Gómez lo que me provocó el deseo de articular un esbozo de lo que podría ser una autobiografía colectiva. Son trabajos que parten de una perspectiva autobiográfica para adentrarse en la memoria colectiva de las mujeres: desde una voluntad de deconstrucción de género, en el caso de Persona-l, y un propósito de visibilización de la historia de la danza femenina valenciana, en el caso de No soy yo. Será después del recorrido, cuando pueda yo constatar que este deseo tiene sentido también a la inversa, puesto que las dos piezas son claros ejemplos del imaginario estético y temático en que nos movemos las creadoras valencianas del siglo XXI.

Esto es especialmente relevante desde el seguimiento de las prácticas autobiográficas pues, como señala Xavier Puchades en un interesante artículo sobre Guadalupe Sáez (otra de nuestras creadoras contemporáneas), si bien existe una tendencia expresiva auto-ficcional de los dramaturgos valencianos desde finales de los años 80 , es notorio que:

[...] la exploración alrededor de lo autobiográfico se generaliza en la segunda década del 2000 y, principalmente, de la mano de mujeres: E. Zapico, A. Albaladejo, D. Belmonte, M. Bayona, P. Pardo, R. Gimeno, S. Gómez o C. M. Gómez. Creaciones unipersonales o colectivas que emplean, entre otros materiales testimoniales: diarios personales o de viaje, cartas y mails, audiovisuales, entrevistas, fotografías e, incluso, gráficas. Diversas miradas sobre la construcción individual y social de la identidad femenina, generacional o cultural, a partir de cuestiones como el escamoteo del pasado histórico tras la Transición, la precariedad laboral o la corrupción urbanística como destructora del espacio de la memoria familiar, entre otras ("Para que no te me olvides" 331).

Veamos cómo desarrollan esto las piezas elegidas. 


\section{Maribel Bayona}

Maribel Bayona Sánchez (Valencia, 1979) es actriz, bailarina y dramaturga, además de Licenciada en Filología Hispánica por la Universidad de Valencia, donde también cursó un doctorado consiguiendo el Diploma de Estudios Avanzados (DEA) con su trabajo "Las salas alternativas valencianas: modelos de gestión, programación y producción”. Su actividad en las artes escénicas valencianas es prolija y diversa. Ha participado en numerosos trabajos de distintas compañías estables o colectivos puntuales y muchas veces en alianzas femeninas como Copia Izquierda (compañía creada por Eva Zapico y Merce Tienda) o Dársena Producciones (de la cual es cofundadora junto a Jessica Belda y José Banyuls).

También hay que destacar su labor de dinamización artística en proyectos de creación como El punto G, junto a Gabi Ochoa, y sus colaboraciones en revistas como Acotaciones en la Caja Negra o Red Escénica, donde participa con sus estudios críticos, pero también en la gestión editorial. Es común también encontrar sus textos teatrales y críticos publicados en otros medios, como Episkenion, Primer Acto o Teina.

Pero si hay un espacio donde Maribel Bayona ha crecido como artista y ha sido capaz de impulsar la creación valenciana, es en el Proyecto Teatro de lo Inestable ${ }^{17}$ sala de programación regular y compañía de exploración de nuevos lenguajes que en el siglo Xxi se ha convertido en un referente de la llamada "escena alternativa" en el Estado español. Dentro del proyecto, cofundado en 2003 junto a Jacobo Pallarés y Rafael Palomares, Bayona ha podido desarrollarse no sólo como creadora, sino que ha vinculado nuestro contexto a innovadores proyectos de gestión, como el International European Theater Meeting (IETM). También ha impulsado la creación valenciana a través de convocatorias de residencias como los "Graneros de Creación", y fomentado la futura comunidad teatral a través de encuentros regulares como "Inestables por la Educación".

Como creadora -dentro y fuera del contenedor de Espacio Inestable- se le conocen desde 2006 numerosos textos y dramaturgias firmados en solitario. Entre sus últimos trabajos destacan: Un acuerdo, un trato o lo que coño sea (2015), Sometimes (2015, coautora), L'instant abans que tot acabe (2016), El acto más hermoso del mundo (2017, co-creadora) y L'orquestra del silencio (2017), texto con el que participó en Insula Dramataria, el primer proyecto de residencias para autoras organizado por el IVC que mencionábamos al inicio. Destaca en todos ellos la exploración postdramática, la interdisciplinariedad de los lenguajes, las posibilidades de lo real, la búsqueda liminal, los relatos confesionales, en unas creaciones que apelan a lo colectivo desde su subjetividad.

17 Respecto a la transdisciplinariedad, es interesante la presentación del proyecto que hacen en su página web: Proyecto Inestable. Teatro, Danza y otros contaminantes. 


\section{Persona-l}

Persona-l, estrenada en otoño de 2010, es la primera pieza en la que Maribel Bayona asume la creación en solitario, aunque como ella misma narra: "trabajaba en escena sola y no sola" (Bayona, Entrevista). Porque, si hay algo que define a esta artista es su predisposición a la colectividad artística, posicionamiento ideológico que defiende desde su Proyecto Teatro de lo Inestable.

Dicho de otro modo, se advierte una colectividad sostenida, que, sin embargo, sostiene también búsquedas propias como la de Persona-l. Este trabajo se enmarcó dentro del eje temático "Persona", convocado como línea transversal de la actividad anual del Proyecto Inestable. ${ }^{18}$ Es en este sentido que Maribel Bayona afirma no haber trabajado sola, sino en el marco de una propuesta comunitaria que le proporciona la infraestructura necesaria para llevar adelante la creación. Lo maravilloso, no obstante, es la capacidad de la artista de convertir dicha circunstancia en el armazón estético e ideológico de la pieza, abordando así la pregunta sobre su propia identidad como una de-construcción colectiva, incorporando su búsqueda a esa premisa que sintetiza Estrella de Diego al hablar de escrituras autobiográficas: "contar la biografía de los otros es con frecuencia un modo eficaz de relatar la propia autobiografía" (177).

Por ejemplo, en este caso, la artista utilizó biografías de sus propios compañeros/as grabadas en forma de testimonios audiovisuales (fruto de un cuestionario en el que Bayona los conmina a reflexionar sobre su propia identidad de género). Dichos videos se proyectan durante la pieza con distintas estrategias evocadoras de sentidos (desde la sobreimpresión directa en el cuerpo de la performer, hasta la sustitución de su propia imagen en la silla donde ha estado sentada), generando, además de imágenes lumínico-físicas de gran belleza, sugerencias sobre la alteridad -otro de los conceptos que sobrevuelan la propuesta.

Pero además del tema de la alteridad o la indagación autobiográfica, Persona- $l$ es, ante todo, un cuestionamiento de la construcción de género. Parte de una fórmula matemática ficcional con la que inicia el espectáculo $(\mathrm{h} / \mathrm{m} \times \mathrm{sc}) \mathrm{cf}=\mathrm{p}$ (donde $\mathrm{h}=$ hombre, $\mathrm{m}=$ mujer, $\mathrm{sc}=$ sociedad del conocimiento, $\mathrm{cf}=$ capitalismo de ficción, $\mathrm{y} \mathrm{p}=$ persona). Ecuación que contextualiza la síntesis del mundo de una creadora que arranca su discurso compartiendo explícitamente la búsqueda estético-ideológica de su trabajo: se fijará en la dualidad $\mathrm{h} / \mathrm{m}$ en relación al resultado p, "persona".

Oposición que se va a transformar en acciones performáticas duales: dos pelotas, roja y verde $-i$ diferentes aunque iguales?, ¿iguales aunque diferentes?-. Un par de zapatos, uno

18 Cada año, el proyecto plantea un eje alrededor del cual se ordena toda la actividad: creaciones en residencia, programación, publicaciones y, especialmente, la propuesta artística anual de la compañía. 
INVESTIGACIÓNTEATRAL

Revista de artes escénicas y performatividad

Vol. 9, Núm. 14

octubre 2018-marzo 2019
Bailando memoria(s) de mujer: dos escenas autobiográficas en territorio valenciano

Anna Albaladejo López

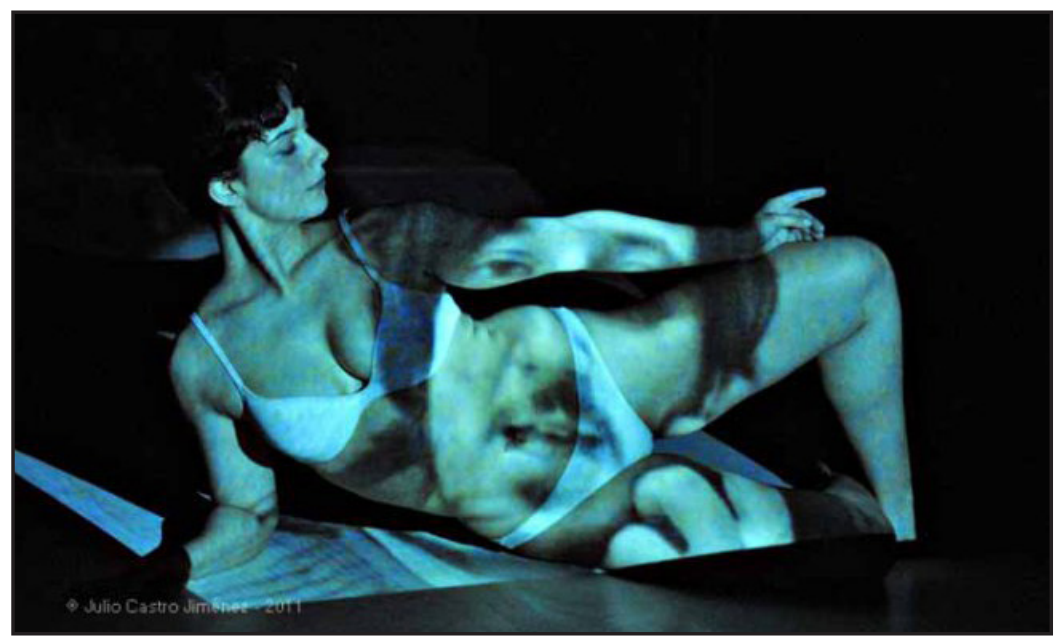

Testimonios proyectados sobre el cuerpo de la intérprete. Espacio Inestable. Valencia, España, 2011. Fotografía de Pau Gaya.

de tacón y otro plano, con los que genera un caminar desigual que la ejecutante acaba transformando en movimiento coreográfico de gran significación. Como ella misma comenta en entrevista, sus esfuerzos han ido encaminados a transponer en imágenes y acciones toda la teoría elaborada durante el proceso: "Una teoría sobre la construcción de los géneros que tan reveladora ha sido para entenderme a mí misma” (Bayona, Entrevista).

Acciones, imágenes y textos que no sólo desnudan referentes teóricos tan necesarios como Judith Butler, Michel Foucault, Pierre Bordieu o Beatriz Preciado, sino que se actualizan en referencia a la misma memoria personal e identidad biográficas de la artista. Porque en la búsqueda de Maribel Bayona se intuye aquello que Estrella de Diego define como: "una guerra abierta contra una propuesta de subjetividad única [...] con la esperanza de reencontrar al sujeto múltiple y fracturado", donde la autobiografía es una "confidencia y promesa reiterada de intimidad" (36).

Ello lleva a la artista a incluir materiales personales en forma de sueños, narraciones autobiográficas, confesiones o incluso videos de su propia familia. Materiales que juegan al mismo tiempo como ejercicio de sinceridad y como cuestionamiento ideológico de la construcción social, e incluso ficcional, de nuestra identidad. Así, durante la presentación inicial se cuestiona la misma nomenclatura formal de nuestra identidad: "Me llamo Maribel Bayona, mejor dicho, me llamo Maribel Bayona Sánchez, aunque mi DNi pone María Isabel Bayona Sánchez". ¿Somos un nombre, un logotipo, una imagen inscrita a fuerza de repetición?, parece espetar la actriz mientras recita una y otra vez su nombre, enganchada en movimientos repetitivos de los que parece no poder escapar.

Sin embargo, es la reflexión final la que resquebraja totalmente cualquier proyección de inocencia sobre una artista, cuya dulzura en la voz y el movimiento podrían guiar al 
INVESTIGACIÓNTEATRAL

Revista de artes escénicas y performatividad

Vol. 9, Núm. 14

octubre 2018-marzo 2019
Bailando memoria(s) de mujer: dos escenas autobiográficas en territorio valenciano

Anna Albaladejo López

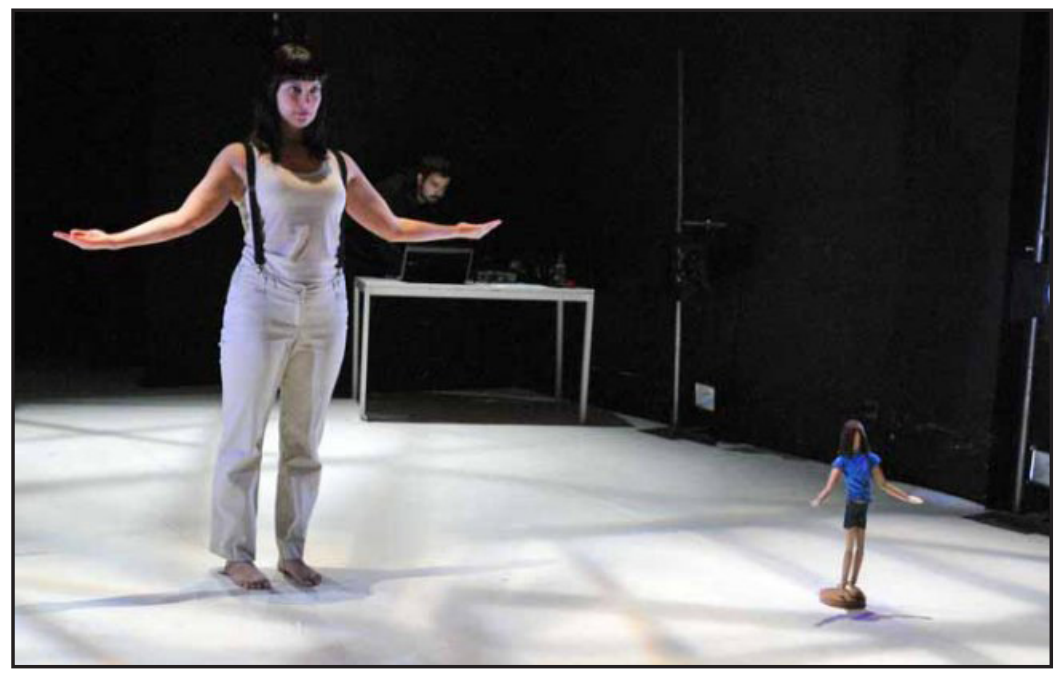

Multiplicaciones del cuerpo/ identidad. Espacio Inestable. Valencia, España, 2011. Fotografía de Pau Gaya.

espectador hacia una empatía casi infantilizadora: "Se supone que debería hablar de mí, de mí... pero ¿quién sabría si realmente hablo o no de mí? A lo mejor todo lo que cuento son mentiras, ¿no?”. Y es que, como ella misma sostiene: ni le gustan las actitudes paternalistas, ni quiere quedarse en un personaje, mujer o artista, proyectado desde su rol de género.

La denuncia es transformada en acciones performáticas, por ejemplo, mediante el desdoblamiento de la actriz en una marioneta de madera, cuyos movimientos son traspasados al cuerpo de la mujer, abocada a transformarse en maniquí parlante. La marioneta multiplica, a su vez, la imagen inicial de la artista sepultada entre capas de ropa. Anti-striptease de actriz y marioneta, que lanza reflexiones diversas sobre la imposición del desnudo femenino o la necesidad de un desnudo metafórico de las vestimentas impuestas...

Otras secuencias de acción completan una estructura espectacular fragmentaria y sin pretensiones aristotélicas, que sin embargo es descrita como circular por la misma artista (Bayona, Entrevista). Ella parte de su dimensión personal, explora las capas de los discursos de los otros (textos teóricos, canciones, poemas, tópicos sobre mujeres y hombres, reflexiones personales de sus compañeros, etcétera) hasta volver de nuevo al yo. Un "yo" otro, seguramente.

Un "yo" que se multiplica una vez más al final de la escena con la intervención de otro cuerpo, esta vez masculino: el del creador y técnico de luces Pedro Lozano, que participa del desdoblamiento discursivo con un profundo monólogo sobre su posibilidad/imposibilidad de llorar. Una vez más, la experiencia personal concreta una imposición de género.

El resultado es un trabajo aparentemente sencillo por su sobriedad de recursos y su discurso directo y sincero, pero cuyo valor se encuentra especialmente en la capacidad de 
la artista de articular discurso, movimiento y dispositivo escénico en una reflexión performática y política que obliga a los espectadores a enfrentarse a aquella estrategia radical autobiográfica que De Diego resume como:

[...] mirarse en el espejo para darse de bruces con una imagen fracturada, una historia, la propia, que se rompe y se fragmenta, a su manera un acto fallido con algo de fracaso cada vez; cierto autorretrato que podría ser el de cualquiera" (41).

Conseguir esto, cuando hablamos de de-construir el género, no es tarea fácil.

\section{Sandra Gómez}

Sandra Gómez (1975) es licenciada en Arte Dramático por la Escuela Superior de Arte Dramático (ESAD) de Valencia con una amplia formación en danza contemporánea en Valencia y Bruselas. Cuenta con un Máster en Producción Artística por la Facultad de Bellas Artes de Valencia, en el que inicia una investigación, precisamente, sobre proyectos escénicos autobiográficos. En dicho estudio se encuentra actualmente profundizando, y se ha convertido en uno de los ejes de sus búsquedas como creadora.

Como bailarina y actriz ha participado en numerosos proyectos por toda Europa, normalmente con algunos de los artistas responsables de la expansión de la escena (como Pippo del Bono, con quien participó en 2006 en Thierry Salmon; Ion Munduate y Blanca Calvo, en el proyecto Mugatxoan en 2008; o la coreógrafa Cláudia Días, con quien colaboró en 2010 en En esta parte esquinada de la península). Como investigadora-creadora ha estado siempre vinculada a ARTEA y a mujeres de la danza del norte de la península ibérica, como Idoia Zabaleta o Isabel Naverán, posibilitando la llegada de estos referentes a nuestra comunidad creativa valenciana. En esta inquietud por la exploración de la escena y la superación de los modelos espectaculares y dramáticos de corte tradicional, Sandra Gómez cofundó en 2001, junto a Vicente Arlandis, el colectivo Losquequedan, cuyos trabajos en torno al juego, las prácticas de realidad y la inclusión del espectador como participante, han servido de escuela para muchos grupos y creadores valencianos.

Desde 2012 lleva a cabo su propia investigación, desplazando el centro de sus exploraciones al soporte corporal, puesto que Sandra es, ante todo, una artista que experimenta y crea desde su propio cuerpo. Esta identificación la ha llevado al estudio académico de las prácticas autobiográficas, que se transpone a sus creaciones más recientes. Tal es la perspectiva que plantea sobre su propia historia (personal o artística) en Tentativa (2012), donde confronta su memoria de la danza con la historia oficial; o en torno a la memoria de 
las/os participantes en Tentativa and Guest (2014), donde la misma historia de la danza es vinculada a la biografía de los asistentes a un taller de creación guiado por ella misma; o en torno a la de los mismos espectadores, como en The love thing piece (2013), donde la artista explora la descentralización del yo y el reflejo para explicarse su propia identidad.

Si bien podría haber elegido cualquiera de estos trabajos como materia del presente artículo - pues en todos ellos está presente la cuestión autobiográfica y todas fueron piezas capaces de suscitar en los asistente una verdadera experiencia emocional, por sus consecuciones estéticas y energéticas-, es sin duda No soy yo (2016) el trabajo que mejor sustenta la idea de una escritura autobiográfica colectiva de las mujeres creadoras de mi territorio.

\section{No soy yo}

Esta pieza supone la concreción de una búsqueda en la que Sandra Gómez ha transitado un camino de exploración autobiográfica que trasciende los límites del escenario. No es casual que el título de la pieza tome el nombre del ensayo de Estrella de Diego, No soy yo. Autobiografía, performance y los nuevos espectadores, que da cuenta del tránsito de las prácticas autobiográficas que han transformado la idea del sujeto de la modernidad -pretendidamente unitario y parapetado por los discursos del poder-, hacia ese otro sujeto múltiple y fragmentado, inaprehensible como una totalidad compacta, que intuyen las poéticas contemporáneas (De Diego, No soy yo 33-48).

En una búsqueda a través de sus piezas, que la lleva a lo que describe como una "descentralización del yo" (Gómez, Entrevista), Sandra encuentra en este trabajo una nueva estrategia coreográfica/dramatúrgica que suma a las anteriores. En The love thing piece (2013), por ejemplo, trabaja evitando ocupar la parte central del espacio escénico, lo que quiere significar su negación a ocupar los centros discursivos del poder. O en Tentativa and Guest (2014), compone una identidad o centro colectivo al presentar gráficas con porcentajes medios de estadísticas reales sobre los hábitos de baile de los participantes. Estrategias todas ellas que convergen en No soy yo (2016) para proponer un alejamiento del propio yo a través de la memoria de las otras, otras mujeres de la danza donde la bailarina se refleja:

$\mathrm{Al}$ decir que no es ella, o más bien que no es YO, Sandra se quiere inscribir o lo hace, se reconoce inscrita, en el cúmulo de las experiencias de la danza contemporánea. [...] Sandra se reconoce y se apropia en/de ellas, para sin embargo apostar por su autonomía. Cómo ser ELLA sin ser YO, o sabiendo que el YO también son todas ELLAS, que por su cuerpo, como en resonancia, siguen estando (Ribelles Zorita, "Sandra es una estrella" párr. 3-4). 
INVESTIGACIÓNTEATRAL

Revista de artes escénicas y performatividad

Vol. 9, Núm. 14

octubre 2018-marzo 2019
Bailando memoria(s) de mujer: dos escenas autobiográficas en territorio valenciano

Anna Albaladejo López

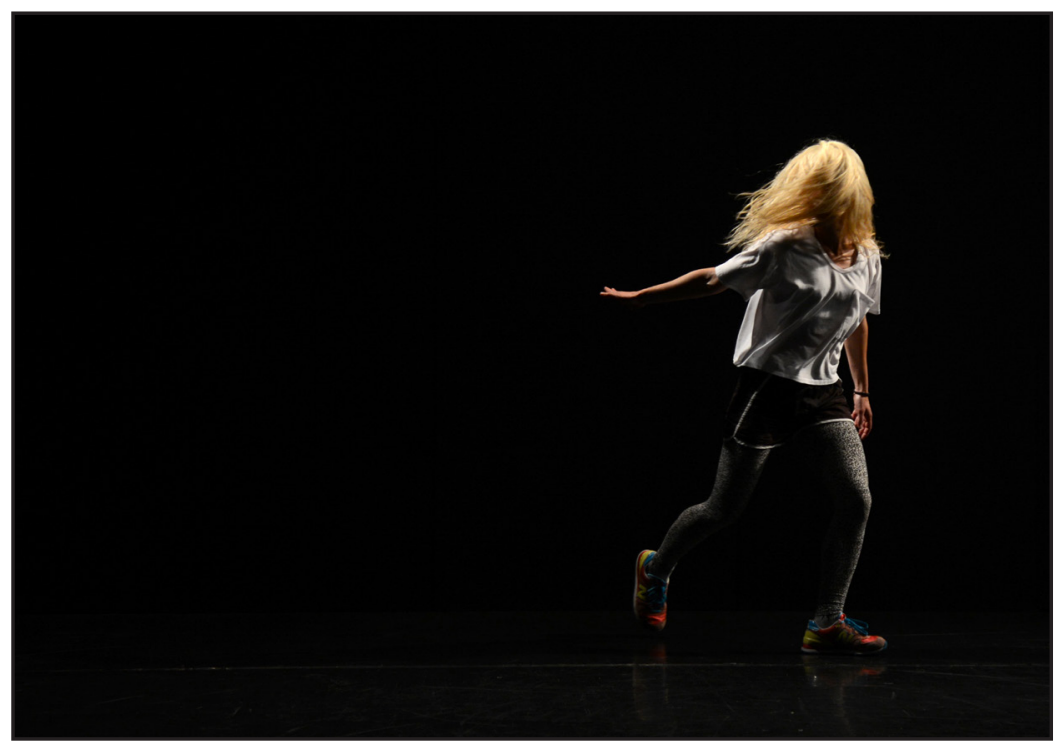

La negación del propio rostro para ser cuerpo colectivo. Valencia, España, 2016. Fotografía de Alain Dacheux

Lo anterior lo consigue a través de tres dispositivos que articulan una dramaturgia muy bien construida por medio de la alternancia de tres tipos de materiales: en primer lugar está la proyección sobre la pared frontal del teatro de entrevistas audiovisuales a un grupo de bailarinas valencianas, quienes todavía ejercen el oficio aunque pertenecen a generaciones anteriores a la de Sandra Gómez (y cuya trayectoria fue significativa para el desarrollo de la danza contemporánea en nuestra ciudad, especialmente durante los años 90 del siglo pasado). Los testimonios de Amparo Ferrer, Carmen Giménez, Cristina Andreu, Gemma Gisbert y Maite Bacete construyen lo que Sandra nombra como la "nohistoria" de la danza valenciana y, por medio de un cuidadoso cuestionario lanzado por la artista, reflexionan sobre la situación presente y sus deseos de futuro.

Destaca aquí no sólo la visibilización de una historia no contada, sino también el pulso por la renovación de la danza y el desplazamiento de los cánones tradicionales de la excelencia en los cuerpos y las coreografías. Historias y proyecciones personales contadas en primera persona como una identidad colectiva en resistencia, una autobiografía común de las periferias del academicismo institucional en las que Sandra Gómez se reconoce.

Como segundo dispositivo, que da un paso más desde la memoria individual hacia la universal, están los testimonios orales de tres coreógrafas europeas. Mathilde Monnier, Anne Teresa De Keersmaeker y Nicole Beutler reflexionan en su propia lengua sobre la situación de la danza contemporánea actual y las deconstrucciones ideológicas que supone su apuesta por la desarticulación de los códigos tradicionales de la danza. Si bien el primer dispositivo audiovisual es presentado por sí mismo, con la bailarina inmóvil en un extremo 
INVESTIGACIÓNTEATRAL

Revista de artes escénicas y performatividad

Vol. 9, Núm. 14

octubre 2018-marzo 2019
Bailando memoria(s) de mujer: dos escenas autobiográficas en territorio valenciano

Anna Albaladejo López

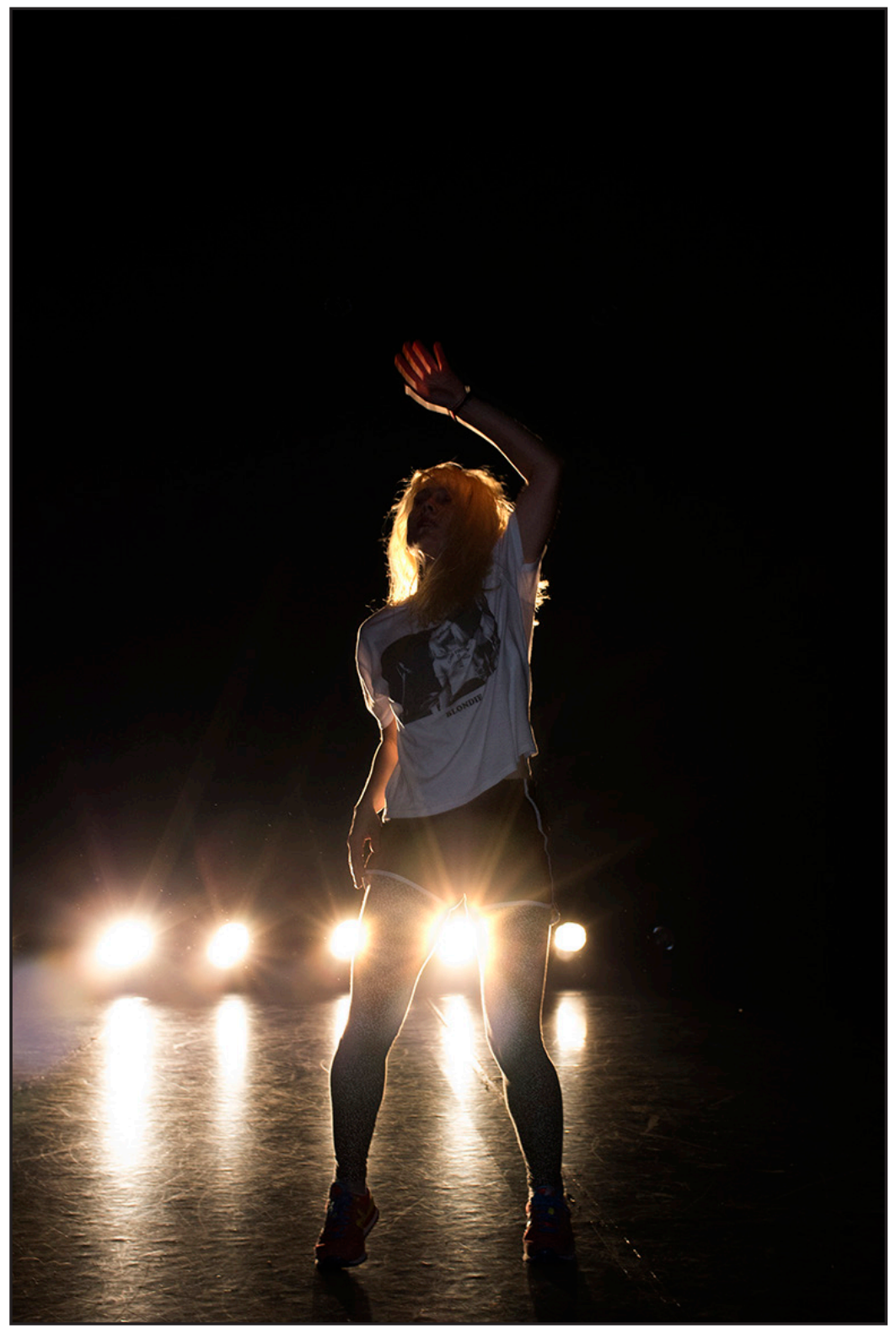

Un yo que surge de las luces de las otras. Barcelona, España, 2016. Fotografía de Marc Tomás.

del escenario, la emisión de las voces de las coreógrafas europeas sí se combina con un trabajo de movimiento danzado que produce la tercera estrategia de memoria colectiva que Sandra Gómez pone en escena.

Este tercer dispositivo, que todavía asciende un peldaño más en la relación de la historia personal con la historia colectiva, consiste en la reinterpretación de 4 coreografías 
de grandes mujeres de la danza postmoderna norteamericana de los años 70: Ivon Rainer, Simone Forti, Lucinda Childs y Trisha Brown. Partituras seleccionadas por su especial relevancia en la incorporación de acciones de la vida cotidiana a la danza, como la misma creadora explicita. Estrategia de movimiento que Sandra Gómez ya ha reivindicado en trabajos anteriores y que no podemos dejar de asociar con un deseo latente de incorporar la dimensión real a la escena. Por ejemplo en Tentativa (2012), donde la artista no persigue la danza como un acto estético, sino que investiga esa necesidad de bailar inherente a todo ser humano.

Volviendo a No soy yo (2016), la reproducción en bucle de las coreografías postmodernas se convierte, en palabras de la misma creadora, en "un proceso de des-subjetivación desde la copia y reapropiación de los movimientos de las otras" (Gómez, Entrevista). Esto tiene una especial relevancia desde la perspectiva autobiográfica que nos ocupa, porque de alguna forma Sandra baila la memoria de la danza: las memorias de otros cuerpos de los que se reapropia haciéndolos presentes, a los que reinterpreta para hacerlos formar parte de una identidad contemporánea -la de Sandra Gómez, pero también la de una danza que se proyecta hacia el futuro-.

Esta metáfora (que se transforma en una poderosa coreografía final en la que Sandra Gómez va generando nuevos movimientos, nuevas apuestas de corporalidad y nuevos significados donde la multiplicidad de ecos de las partituras corporales reproducidas - de los otros yos- atraviesan su cuerpo) va generando una fisicidad propia y efectiva donde, como ella misma confiesa, "aunque parto, de 'no ser yo', esto me ha llevado a ser muy yo" (íbid.). Un "yo" que Sandra hace cuerpo, movimiento multiplicado en la danza de sus antecesoras, donde es tan cierto que la bailarina hace justicia poética a estas mujeres negadas por la historia oficial, como que - a través de ellas- la artista escribe su propia historia. Porque -parafraseando a De Diego- podemos decir que "Uno escribe - una baila- la Historia también para poner en orden la propia vida" (No soy yo 177).

\section{Conclusiones y otros movimientos coreográficos}

Como cierre de este estudio, podemos concluir que las dos piezas analizadas, Persona-l (2011) de Maribel Bayona y No soy yo (2016) de Sandra Gómez, ponen en escena la síntesis de movimientos que las mujeres creadoras valencianas hemos recorrido en las últimas décadas. Movimientos personales y disciplinales que han transformado las prácticas valencianas hacia el intercambio heterogéneo de lenguajes y estructuras de creación, expansiones de la escena y un mayor protagonismo de las mujeres en la comunidad creativa de las Artes Escénicas, ahora Artes Vivas. Ambas piezas son ejemplos de una de las búsquedas 
más transitadas por las creadoras valencianas de las últimas décadas, que hemos partido de nuestro cuerpo y memoria para articular estéticas y discursos críticos, lecturas diversas del mundo y desplazamientos de los centros de poder (no solamente en lo relativo al género).

Es importante entender que estas dos autoras participan de un desplazamiento de la centralidad común a artistas de muchos otros territorios, cuya auto-referencialidad no es más que un camino de vaciado, de multiplicación incluso, donde los cuerpos presentes y ausentes tienen la posibilidad de articular su relato - un relato que, sin duda, será colectivo y tendrá la potencia y la humildad de hablar en primera persona-. Un entrecruzamiento de las memorias y los cuerpos negados por la historia pasada y presente que se refleja en artistas y propuestas de todas las geografías y que, en el caso mexicano, suscita la referencia al trabajo de Lukas Avendaño, cuya maravillosa pieza No soy persona, soy mariposa (2015) confluye, desde su propia resistencia, con las subversiones identitarias y de género de los trabajos hoy presentados.

Como cierre de este escrito, sólo me resta sumarme a estas prácticas autobiográficas colectivas diciendo: No soy investigadora/creadora, soy creadora/investigadora. Y su reflejo.

\section{Bibliografía}

Associació de Professionals de la Dansa de la Comunitat Valenciana. "Danzar en Precario: el sector de la Danza en la Comunidad Valenciana". Universitat de València. 16 de octubre de 2015, en línea. Consultado el 26 de agosto de 2018.

Bayona, Maribel. Entrevista personal con Anna Albaladejo. 28 de septiembre de 2017. Archivo de texto.

"Danzar en Precario: el sector de la Danza en la Comunidad Valenciana". Associació de Professionals de la Dansa de la Comunitat Valenciana (APDCV), APDCV, 16 de octubre de 2015, en línea. Consultado el 26 de agosto de 2018.

De Diego, Estrella. No soy yo. Autobiografía, performance y los nuevos espectadores. Madrid: Siruela, 2011.

Giménez Morte, Carmen. La danza contemporánea en la Comunidad Valenciana. Los primeros pasos. Valencia: Centre Coreogràfic C.V., 2001.

Gómez, Sandra. Entrevista personal con Anna Albaladejo. 21 de septiembre de 2017. Archivo de texto.

Ortiz, Rubén. Escena expandida. Teatralidades del siglo XXI. Ciudad de México: Conaculta, 2015. 
INVESTIGACIÓNTEATRAL

Revista de artes escénicas y performatividad

Vol. 9, Núm. 14

octubre 2018-marzo 2019
Bailando memoria(s) de mujer: dos escenas autobiográficas en territorio valenciano

Anna Albaladejo López

Pardo, Patricia. “Dona i creació escénica al Pais Valencià (2005-2014)”. L'aiguadolç, núm. 45, 2016, pp. 29-44.

Puchades, Xavier. "Para que no te me olvides, de Guadalupe Sáez: Autoficción del duelo". Teatro hispano y su puesta en escena: estudios en homenaje a Josep Lluís Sirera Turó. Eds. José Luis Canet, Marta Haro, John London y Biel Sansano. Valencia: Publicaciones de la Universitat de València, 2017, pp. 325-328.

Ribelles Zorita, Santiago. "Sandra es una estrella de rock". "Mambo", Teatron, Libre comunidad de artes vivas, 20 de octubre de 2016, párrs. 3-4, en línea. Consultado el 26 de agosto de 2018.

Rosselló, Ramón. "Más allá de la interpretación: nuevas creadoras en el teatro valenciano actual". Telón de Fondo, núm. 19, 2014, pp. 83-107.

Sánchez, José Antonio. El teatro en el campo expandido. Barcelona: Museo de Arte Contemporáneo de Barcelona, 2008, en línea. Consultado el 26 de agosto de 2018.

Vidales, Raquel. "El año en que estallaron las dramaturgas". El País, 30 de abril de 2016, en línea. Consultado el 26 de agosto de 2017. 